\title{
Optimization of process parameters for electrophoretic deposition in CNTs/carbon fiber hybrid composites
}

\author{
Y. Q. Wang ${ }^{1}$, J. H. Byun ${ }^{2}$, B. S. Kim ${ }^{2}$ \& J. I. Song ${ }^{1}$ \\ ${ }^{I}$ Department of Mechanical Engineering, Changwon National University, \\ South Korea \\ ${ }^{2}$ Composite Materials Group, KIMS, South Korea
}

\begin{abstract}
Carbon nanotubes (CNTs) have attracted a great deal of interest in the development of high-performance engineering composites, due to their exceptional physical, mechanical, electronic and thermal properties. Incorporation of CNTs into polymer has shown great improvements in the functional property, however, the enhancement of the mechanical property was insignificant compared with that of micro-sized fiber reinforced polymers. In order to realize the application of composites for structural and multifunctional parts, it is necessary to develop hybrid composites with micro- and nano-sized reinforcements. CNT reinforced hybrid composites have been studied in several ways: the addition of CNTs to a matrix with various dispersion methods, the growth of CNTs on substrate reinforcements, CNT sprays, etc. In this study, the electrophoresis deposition (EPD) method has been applied to deposit CNTs on a carbon fabric. By applying an electric field between a copper plate and a substrate, the negatively charged CNTs in a suspension move toward a carbon fabric. The controllable parameters in the EPD process are identified as the deposition time, the voltage, the contents of the CNTs, and the distance between the copper plate and the carbon fabric. In order to determine the optimal process conditions, the Taguchi method for the statistical design of experiment (DOE) has been utilized. Since the interlaminar shear strength (ILSS) of the hybrid composites is associated with the amount and the degree of distribution of the CNTs, it was selected as the response for the analysis of means (ANOM) and signal to noise $(\mathrm{S} / \mathrm{N})$ ratio. The ILSS was measured by short-beam test according
\end{abstract}


to ASTM 2344. The composite sample was fabricated by the vacuum-assisted resin transfer molding (VARTM) process. In addition, the distribution of CNTs was examined by scanning electron microscopy (SEM). By utilizing statistical software MINITAB 14 for DOE, the optimal deposition conditions have been determined.

Keywords: carbon nanotubes, electrophoretic deposition, interlaminar shear strength, optimization, Taguchi method, signal to noise ratio.

\section{Introduction}

Carbon nanotubes (CNTs), since their discovery in 1991 [1], have attracted a great deal of interest due to their remarkable physical, mechanical, electronic and thermal properties [2]. In recent years, many efforts have been carried out in exploiting these properties by incorporating carbon nanotubes into some form of matrix. In addition to the researches of $\mathrm{CNTs} /$ ceramic and $\mathrm{CNTs} /$ metal composites [3-6], a wide range of polymer matrices have also been employed, such as polyamides [7], polyimides [8], epoxy [9], polyurethane [10] and polypropylene [11]. These polymer-based nanocomposites derive their high performance at low filler volume fractions due to the high strength, high aspect ratio and high surface area to volume ratio of the nano-sized particles. Moreover, CNTs have promoted many studies on fabricating field emission films. The electrophoretic deposition (EPD) technique, with a wide range of novel applications in the processing of advanced ceramic materials and coatings [1214], has recently gained increasing interest both in academia and industrial sectors, not only because of the high versatility of its use with different materials and their combinations but also because of its cost-effectiveness, requiring simple apparatus.

In this study, the EPD technique has been applied to deposit CNTs on a carbon fabric to form a nano/micro-scale hybridized reinforcement. Since the properties of the hybrid composites by the EPD process depend on the contents and dispersion of CNTs, it is crucial to identify the key processing parameters and to determine the optimal conditions of the EPD process. For the optimization of design parameters, the statistical design of experiment (DOE) by the Taguchi method [15-16] has been applied. The method was originally proposed as a means of improving the quality of products through the application of statistical and engineering concepts. Since experimental procedures are generally expensive and time consuming, the need to satisfy the design objectives with the least number of tests is clearly an important requirement.

In this study, following the steps of the Taguchi method, nine experiments of EPD processing were conducted. The microstructures of the deposited carbon fabrics were observed by scanning electron microscopy (SEM). The interlaminar shear strength of the multi-scale hybrid composites was tested and chosen as the response for the analysis of means (ANOM) and signal to noise $(\mathrm{S} / \mathrm{N})$ ratio. The statistical software MINITAB 14 was used for the DOE, based on the Taguchi method. 


\section{Design of experiment and experimental procedures}

\subsection{Determinations of controllable parameters and their levels}

The key parameters of EPD processing are the deposition time (T), the voltage (V), the content of CNT in wt\% (W) in suspension, and the distance (D) between the carbon fabric and the copper plate. They were chosen as the four considerable parameters to conduct the design of experiment. For each parameter, three levels were set as shown in Table 1 . These settings define the extent of the data collection required for each controllable parameter.

\subsection{Taguchi method for design of experiment}

The Taguchi method is a traditional approach for robust experimental design that seeks to obtain the best combination of parameters/levels with the lowest societal cost solution to achieve customers' requirement. In addition, special orthogonal arrays will be applied to optimize different kinds of DOE. As 4 parameters $/ 3$ levels considered, a total of nine experiments were necessary. A $L_{9}(3)^{4}$ orthogonal array was selected to proceed with the experiments as shown in Table 2. Moreover, the optimal process parameters are determined by the analysis of response data, such as the ANOM and $\mathrm{S} / \mathrm{N}$ ratio.

Table 1: $\quad$ Design parameters and their levels.

\begin{tabular}{|c|c|c|c|c|c|}
\hline Parameters & Unit & Symbol & Level 1 & Level 2 & Level 3 \\
\hline Time & min & $\mathrm{T}$ & 3 & 5 & 10 \\
\hline Voltage & volt & $\mathrm{V}$ & 20 & 40 & 60 \\
\hline CNT wt. $\%$ & - & $\mathrm{W}$ & 0.05 & 0.1 & 0.5 \\
\hline Distance & $\mathrm{cm}$ & $\mathrm{D}$ & 1 & 2 & 3 \\
\hline
\end{tabular}

Table 2: $\quad$ Design tables and their levels.

\begin{tabular}{|c|c|c|c|c|}
\hline No. of Exp. & $\mathrm{T}(\mathrm{min})$ & $\mathrm{V}(\mathrm{V})$ & $\mathrm{W}(\mathrm{CNT}$ wt. \%) & $\mathrm{D}(\mathrm{cm})$ \\
\hline 1 & 3 & 20 & 0.05 & 1 \\
\hline 2 & 3 & 40 & 0.1 & 2 \\
\hline 3 & 3 & 60 & 0.5 & 3 \\
\hline 4 & 5 & 20 & 0.1 & 3 \\
\hline 5 & 5 & 40 & 0.5 & 1 \\
\hline 6 & 5 & 60 & 0.05 & 2 \\
\hline 7 & 10 & 20 & 0.5 & 2 \\
\hline 8 & 10 & 40 & 0.05 & 3 \\
\hline 9 & 10 & 60 & 0.1 & 1 \\
\hline
\end{tabular}




\subsection{Experimental details}

\subsubsection{Selection of materials}

Multi-wall carbon nano-tubes (MWCNTs) CM-100 (Hanwha Nanotech Corporation) were used in this study, which was produced using the thermal chemical vapor deposition (CVD) process. The diameter of CNTs is $10-15 \mathrm{~nm}$. The carbon fabrics for EPD have a size of $110 \mathrm{~mm}$ by $90 \mathrm{~mm}$. For the fabrication of composite samples, epoxy resin (YD-128) and hardener (KBH-1089) with a mixing ratio of 10 to 9 were used.

\subsubsection{Preparation of suspension}

Anodic EPD process was utilized in this study to avoid the electrolysis of copper plate. In order to functionalize CNTs in negative charge, they were treated in the strong acid solution, resulting in the carboxylic functional group on the surface of CNTs. The chemical structures of CNTs and modified CNTs are shown in Fig. 1. The acid treated CNTs were mixed with distilled water in a proper ratio as designed to prepare the suspension. For the high quality of dispersion, the mixture was ultrasonicated for $35 \mathrm{~min}$ after $10 \mathrm{~min}$ mechanical stirring with a speed of $450 \mathrm{rpm}$.

\subsubsection{Electrophoretic deposition}

EPD is achieved via the motion of charged particles, dispersed in a suitable solvent or aqueous solution, towards an electrode under an applied electric field. Electrophoretic motion of charged particles during EPD results in the accumulation of particles and the formation of a homogeneous and rigid deposit on the relevant electrode. The success of EPD is based on its high versatility, which facilitates its use with different materials and combinations of materials. In addition, EPD is a rapid, cost-effective method that requires simple equipment enabling material layers (thin and thick films) to be made in only seconds or minutes. Moreover, EPD has a high potential for scaling up to large product volumes and sizes.

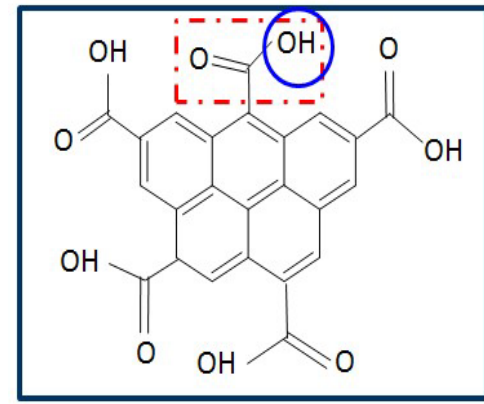

(a)

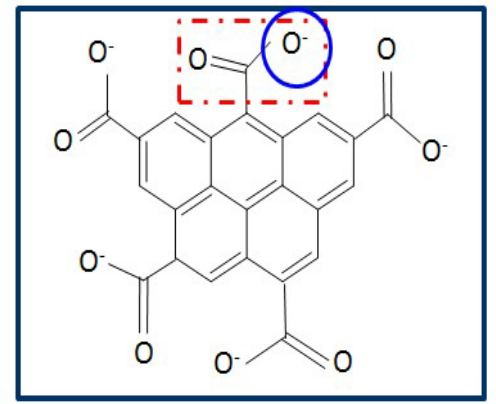

(b)

Figure 1: The chemical structures of CNTs (a) before oxidation and (b) after oxidation. 


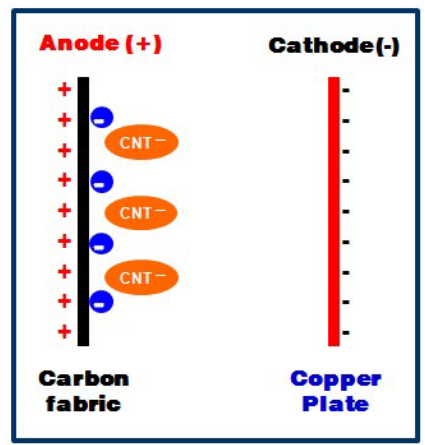

Figure 2: $\quad$ Schematic illustration of anodic EPD.

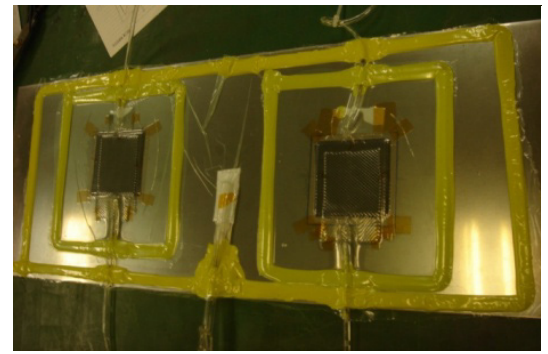

(a)

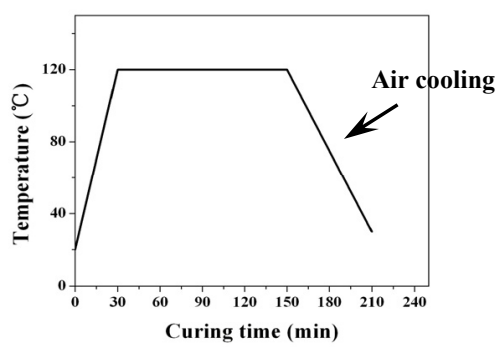

(b)

Figure 3: Fabrication of composite samples: (a) VARTM process; (b) timetemperature curing curve for composite.

Copper plates and carbon fabrics were used as an anode and a cathode in the anodic EPD, respectively. When a constant DC voltage was applied to the electrodes, the acid treated CNTs were deposited on the surface of the anode electrode. Figure 2 shows the schematic illustration of the anodic EPD. For each designed experiment, 12-ply deposited carbon fabrics were prepared.

\subsection{Manufacturing CNTs/carbon fabric composite}

CNTs/carbon fabric composites were prepared by VARTM, in which the mixture of resin and hardener is pulled into the mould by negative pressure, and impregnates the deposited carbon fabrics as shown in Fig. 3 (a). The curing curve of the composite is shown in Fig. 3 (b).

\subsection{Interlaminar-shear strength (ILSS) testing}

For the measurement of interlaminar shear strength (ILSS) of the composite, the short-beam test has been conducted. The length, width, and thickness of the test specimens were $20 \mathrm{~mm}, 5 \mathrm{~mm}$, and $2.5 \mathrm{~mm}$, respectively. The span length was $10 \mathrm{~mm}$, and the crosshead speed was $1 \mathrm{~mm} / \mathrm{min}$ according to ASTM 2344. 


\section{Results and discussion}

\subsection{Interlaminar shear strength and microstructure}

Figure 4 presents the ILSS of the composite samples. The values of No.5 and No.9 experiments were much lower than the others. High level of strength has been obtained for the cases of No.1, No.2, and No.8 experiments. Figure 5 shows the SEM images of No. 1 and No.9 experiments. Although the No. 9 experiment shows the higher population of CNTs deposition on a carbon fabric compared to No. 1 experiment, more agglomerations resulted in the strength reduction.

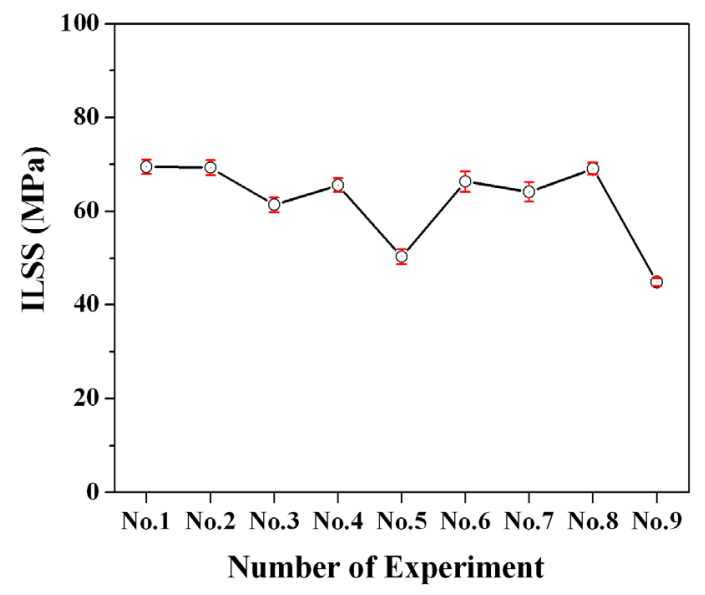

Figure 4: ILSS responses for each design experiment.

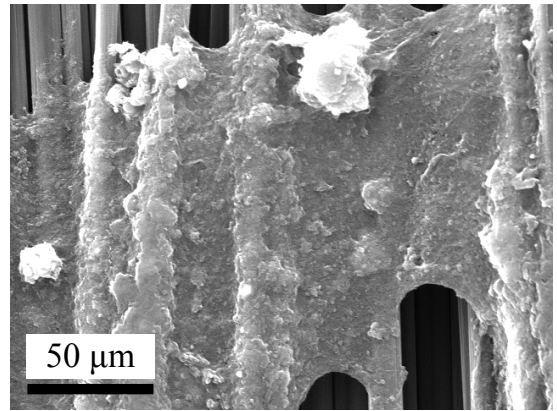

(a)

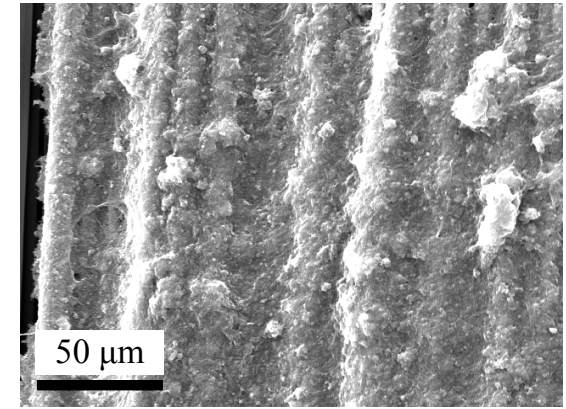

(b)

Figure 5: SEM images of the deposited carbon fabrics with the conditions of (a) No.1 experiment and (b) No.9 experiment. 
Table 3: $\quad$ ANOM for design parameters.

\begin{tabular}{c|c|c|c|c}
\hline \multirow{2}{*}{ Parameter } & \multicolumn{3}{|c|}{ Level } & \multirow{2}{*}{ Optimum } \\
\cline { 2 - 4 } & 1 & 2 & 3 & level \\
\hline $\mathrm{T}$ & 66.73257 & 60.76387 & 59.42363 & $\mathrm{~T} 1$ \\
\hline $\mathrm{V}$ & 66.40901 & 62.91733 & 57.59367 & $\mathrm{~V} 1$ \\
\hline $\mathrm{W}$ & 68.32533 & 59.96757 & 58.62717 & $\mathrm{~W} 1$ \\
\hline $\mathrm{D}$ & 54.94750 & 66.61630 & 65.35627 & $\mathrm{D} 2$ \\
\hline
\end{tabular}

\subsection{Analysis of the means}

To determine the optimum condition of the EPD process, the ANOM and the analysis of $\mathrm{S} / \mathrm{N}$ ratio have been carried out based on the results of the nine experiments.

The results of ANOM are summarized in Table 3. The values are the average of three ILSS corresponding to the same level of a specific parameter and different levels of other parameters. For example, the first value (66.73257) corresponding to the $3^{\text {rd }}$ column and the first row of Table 3 is the average of three values of No.1, No.2, and No.3 experiments shown in Table 2. In Table 3, the maximum values of three levels of each parameter were selected. This combination can be considered as the optimal deposition conditions because higher ILSS is expected.

\subsection{Analysis of the $\mathrm{S} / \mathrm{N}$ ratio}

The $\mathrm{S} / \mathrm{N}$ ratio can be considered as the objective function for matrix experiments. The objective functions can be classified into three categories such as the larger the better type, the smaller the better type and the nominal the best type. S/N ratios of these three different cases are calculated using the following equations:

$$
\begin{gathered}
\eta=-10 \log \frac{1}{n}\left(\sum_{\mathrm{i}=1}^{n} 1 / \mathrm{y}_{i}^{2}\right) ; n=9 \\
\eta=-10 \log \frac{1}{n}\left(\sum_{\mathrm{i}=1}^{n} \mathrm{y}_{i}^{2}\right) ; n=9 \\
\eta=-10 \log \frac{1}{n}\left(\sum_{\mathrm{i}=1}^{n}\left(\mathrm{y}_{i}-m\right)^{2}\right) ; n=9
\end{gathered}
$$

where $\eta$ is the $\mathrm{S} / \mathrm{N}$ ratio, $n$ is the number of experiments, $y_{i}$ is the value of shear strength of the $i$-th experiment.

The overall mean value, $m$, of the $\mathrm{S} / \mathrm{N}$ ratios is computed by

$$
m=\frac{1}{n} \sum_{\mathrm{i}=1}^{n} \eta_{i}
$$

The effect of a level $l$ for a parameter $k$ is given by

$$
\left(m_{l}\right)_{k}=\frac{1}{N} \sum_{l=1}^{N}\left(\eta_{l}\right)_{k} \quad ; N=3 ; k=C, L, T, t
$$


Table 4: $\quad \mathrm{S} / \mathrm{N}$ ratios of design parameters: larger is better.

\begin{tabular}{c|c|c|c|c}
\hline & $\mathrm{T}$ & $\mathrm{V}$ & $\mathrm{W}$ & $\mathrm{D}$ \\
\hline Level 1 & 36.47243 & 36.4396 & 36.6898 & 34.6477 \\
\hline Level 2 & 35.60437 & 35.88127 & 35.406 & 36.46727 \\
\hline Level 3 & 35.33377 & 35.0897 & 35.3147 & 36.2956 \\
\hline Delta & 1.13866 & 1.3499 & 1.3751 & 1.81957 \\
\hline Rank & 4 & 3 & 2 & 1 \\
\hline
\end{tabular}

The values shown in Table 4 are the average values of three $\mathrm{S} / \mathrm{N}$ ratios computed by Eqn. (1-a) corresponding to the same level of a specific parameter and different levels of other parameters. When Eqn. (1-a) is selected, it means that the optimum level for a parameter is the level that results in the highest value of $\mathrm{S} / \mathrm{N}$ ratio in the experimental region according to the larger the better type. The larger the better type is used in the present study as it deals with the evaluation of interlaminar shear strength of composites. Furthermore, the combination T1, V1, W1, and D2 were found to be the optimal conditions of EPD process. According to the value of delta, the effect rank of each parameter was determined. Higher rank indicated that the parameter did more contributions on the EPD process.

\section{Conclusions}

The optimal EPD condition for the deposition of CNTs on a carbon fabric was determined based on Taguchi method. Four design parameters, namely, the time, the voltage, the CNTs content in $\mathrm{wt} \%$, and the distance, were considered as the variable parameters with three levels of each. A $L_{9}\left(3^{4}\right)$ orthogonal array was used for the design of experiment. The software MINITAB 14 was used to perform ANOM and $\mathrm{S} / \mathrm{N}$ ratio. From these analyses, the following conclusions can be made:

i. Due to the oxidization in the acid solution, CNTs were successfully deposited on a carbon fabric using an anodic EPD process.

ii. Optimal levels of design parameters are T1V1W1D2, which means that deposition time is $3 \mathrm{~min}$, voltage is $20 \mathrm{~V}$, CNTs $\mathrm{wt} \%$ is $0.05 \%$, and distance between copper plate and carbon fabric is $2 \mathrm{~cm}$.

iii. With the analysis of $\mathrm{S} / \mathrm{N}$ ratio, the rank of four parameters shows that the degree of influence of the design parameters on the strength was in the order of distance $>$ CNTs $w t \%>$ voltage $>$ time.

\section{Acknowledgements}

The authors would like to acknowledge the partial support from the second stage of Brain Korea 21 Project Corps for carrying out this work. The authors also gratefully acknowledge the support from the Korea Foundation for International 
Cooperation of Science \& Technology (KICOS) through a grant provided by the Korean Ministry of Education, Science \& Technology (MEST) in 2007 (No. K20704000090).

\section{References}

[1] Iijima, S., Helical microtubules of graphitic carbon, Nature, 354, pp. 56-58, 1991.

[2] Harris, P.J.F., Carbon nanotubes and related structures-new materials for the twenty-first century, Cambridge, Cambridge University Press, 1999.

[3] Zhan, G.D., Kuntz, J.D., Mukherjee, A.K., Zhu, P.X., and Koumoto, K. Thermoelectric properties of carbon nanotube/ceramic nanocomposites, Scripta Materialia, 54(1), pp. 77-82, 2006.

[4] Chen, X.H., Xia, J.T., Peng, J.C., Li, W.Z., and Xie, S.S., Carbon-nanotube metal-matrix composites prepared by electroless plating, Composites Science and Technology, 60(2), pp. 301-306, 2000.

[5] An, J.W., You, D.H., Lim, D.S., Tribological properties of hot-pressed alumina-CNT composites, Wear, 255, pp. 677-681,2003.

[6] Lim, D.S., You, D.H., Choi, H.J., Jang, H., Effect of CNT distribution on tribological behaviour of alumina-CNT composites, Wear, 259, pp. 539544, 2005.

[7] Zhao, C.G., Hu, G.J., Justice, R., Schaefer, D.W., Zhang, S., Yang, M.S., Han, C.C., Synthesis and characterization of multi-walled carbon nanotubes reinforced polyamide 6 via in situ polymerization, Polymer, 46, pp. 51255132, 2005.

[8] Kim, S., Pechar, T.W., Marand, E., Poly(imide siloxane) and carbon nanotube mixed matrix membranes for gas separation, Desalination, 192, pp. 330-339, 2006.

[9] Gojny, F.H., Wichmann, M.H.G., Fiedler, B., Schulte, K., Influence of different carbon nanotubes on the mechanical properties of epoxy matrix composites - A comparative study, Composites Science and Technology, 65(15-16), pp. 2300-2313, 2005.

[10] Koerner, H., Liu, W.D., Alexander, Mirau, M., P., Dowty, H., Vaia, R.A., Polymer, 46, pp. 4405-4420, 2005.

[11] Seo, M.K., Park, S.J., Electrical resistivity and rheological behaviors of carbon nanotubes-filled polypropylene composites, Chemical Physics Letters, 395, pp. 44-48, 2004.

[12] Sun, J., Gao, L. and Li, W., Colloidal processing of carbon nanotube/alumina composites, Chemistry of Materials, 14(12), pp. 51695172, 2002.

[13] Li, X.H., Niu, J.L., Zhang, J., Li, H.L. and Liu, Z.F., Labeling the defects of single-walled carbon nanotubes using titanium dioxide nanoparticles, Journal of Physical Chemistry B, 107(11), pp. 2453-2458, 2003.

[14] Besra, L. and Liu, M., A review on fundamentals and applications of electrophoretic deposition (EPD), Progress in Materials Science, 52(1), pp. 1-61, 2007. 
300 High Performance Structures and Materials V

[15] Liao, H.C., A data envelopment analysis method for optimizing multiresponse problem with censored data in the Taguchi method, Computers \& Industrial Engineering, 46, pp. 817-835, 2004.

[16] Gaitonde, V.N., Karnik, S.R., and Paulo, J.D., Taguchi multipleperformance characteristics optimization in drilling of medium density fibreboard (MDF) to minimize delamination using utility concept, Journal of Material. Processing Technology, 196(1-3), pp. 73-78, 2008. 